\title{
REVERSAL OF MYOPIC ANISOMETROPIC AMBLYOPIA WITH OCCLUSION THERAPY IN A 25 YEAR OLD
}

\author{
E. MEGBELAYIN, S. M. EKPENYONG, J. AZUNOBI and G. EJIRO \\ Department Of Ophthalmology, University Of Uyo Teaching Hospital, Uyo, Akwa-Ibom State, Nigeria
}

DOI: $\underline{\text { http://dx.doi.org/10.4314/gmj.v48i1.10 }}$

Corresponding Author: Dr. E. Megbelayin

Email:favouredolu@yahoo.com

Conflict of Interest: None Declared

\section{SUMMARY}

Objective: To report a reversal of myopic anisometropic amblyopia with occlusion therapy in a 25 year old.

Design: Case report.

Setting: Eye clinic of a University Teaching Hospital in a metropolitan city.

Participant: an index patient.

Intervention: Occlusion therapy.

Main Outcome Measure: Post occlusion visual acuity.

Results: Presenting unaided visual acuity of right eye: 6/6, left eye: $4 / 60$. Refraction result was: right eye: $0.50 \mathrm{DS}(6 / 6)$, left eye: -3.50DS (6/18). Following day time occlusion therapy of at least 6 hours for about 4 weeks, subjective refraction was: right eye: $-0.5 \mathrm{DS}$ (6/5), left eye: $-3.50 \mathrm{DS}\left(6 / 6^{+3}\right)$.

Conclusion: The remarkable improvement in vision at age 25 years of a patient with myopic anisometropic amblyopia shows that occlusion therapy might still be useful long after amblyogenic period.

Keywords: anisometropia, amblyopia, occlusion therapy, adult.

\section{INTRODUCTION}

Uncorrected anisometropia produces form deprivation and/or abnormal binocular interaction by producing dissimilar images on the foveae. Vision being generally good in the fellow eye, anisometropic amblyopia is often detected later than other forms of amblyopia. Additionally, the amblyopic eye is typically orthotropic. ${ }^{1}$ Age has been a sole criterion for occlusion therapy as a therapeutic option, although scientific facts and anecdotal evidences have continued to deemphasize it.

Amblyopia is a major public health problem with an estimated prevalence in African and non-African settings of 0.4 to 7.3 per cent. ${ }^{2,3}$ It is the most common cause of monocular vision loss in children and young adults. ${ }^{1}$ Early recognition and prompt treatment have been advocated to prevent permanent loss of vision.
However, general apathy to corrective lenses acceptance is a major impediment to reducing vision loss from amblyopia.

\section{CASE REPORT}

A 25-year-old female pharmacist presented to our centre in December, 2012 with a month history of difficulty recognizing faces at far and reading problems. She had lost her prescribed lenses a month earlier. There was associated history of tearing and redness of the eyes. However, there were no headaches or diplopia. At the age of 13 years she commenced use of corrective lenses. She had complained of difficulty with vision especially in the left eye earlier but the parents thought she was too young to use glasses. She had changed her glasses about 10 times for reasons ranging from loss of glasses to poor vision. The last spectacle was obtained about a year ago. Both parents use glasses for reading and sight. The elder sisters use glasses for sight but the brothers will not use glasses despite complaining of poor vision. There was no history of any systemic illness.

On examination, the presenting unaided Snellen's visual acuity (VA) was right eye (OD): 6/6, left eye (OS): 4/60. Refraction result was: OD: -0.50DS (6/5), OS: $3.50 \mathrm{DS}(6 / 18)$. Other than cup-disc-ratio of 0.6 on the right eye as against 0.2 on the left eye, no abnormalities were found. Further examination including dilated fundoscopy, ocular alignment by Hirschberg and cover-uncover test, central visual field and tonometry were within normal limits. A diagnosis of myopic anisometropic amblyopia was made.

The remarkable visual improvement following refraction and growing evidence of post-occlusion vision recovery in adults' amblyopic patients made us attempt occlusion therapy. A tape for at least 6 hours a day for 14 days was used to occlude the better right eye before wearing her new corrective lenses. Patient was well motivated and told what to gain for complying with treatment. 
On day 14 , the refraction was repeated, OD: $-0.5 \mathrm{DS}$ $(6 / 5),-3.50 D S(6 / 9)$. Second 14-day phase of occlusion was then commenced, unfortunately patient reported after 28 days admitting irregularities in the occlusion therapy. We did the third refraction, OD: $-0.5 \mathrm{DS}(6 / 5)$, $-3.50 \mathrm{DS}\left(6 / 6^{+3}\right)$.

\section{DISCUSSION}

Anisometropia as a cause of amblyopia is well established. $^{4-6}$ Amblyogenic period during which an eye is susceptible to amblyopia is what has been a subject of controversy. Even more controversial is the age limit to stop occlusion as a treatment modality. Over the years, there are several reports on outcomes of occlusion therapy in different age groups. ${ }^{4-7}$ It is increasingly being realized that occlusion therapy might still be successful long after amblyogenic period. Fear of failure may have dissuaded many ophthalmologists from attempting the age long treatment modality on grown-up patients.

The level of anisometropia required to cause amblyopia has been well studied. ${ }^{8,9}$ In general, anisohyperopia of more than 1.00 diopter, anisoastigmatism of more than 1.50 diopter cylinder, and anisomyopia of more than 2.00 diopters may result in amblyopia. Anisomyopia was -3.00 diopters in our patient.

Two experienced optometrists refracted the patients using the same refracting unit under the same circumstances making the issues of errors minimal. Again, the huge difference between unaided and post-refraction visual acuities made errors in refraction unlikely. There were two lines improvement in visual acuity $(6 / 18$ to 6/9) following 14 days occlusion of at least 6 hours. Although patient admitted poor compliance to second phase of occlusion, third refraction in the amblyopic eye showed a vision better than 6/6. Perhaps the eye had achieved sufficient photopic stimulations by the time occlusion therapy became irregular.

Successes of occlusion therapy have been reported in patients slightly younger than our patients. Prakash ${ }^{10}$ in an Indian study in 1983 reported visual improvement in 2 myopic patients after occlusion therapy. The first was a 20 year who improved from $6 / 60$ to $6 / 18$. The second aged 22 years improved from $6 / 60$ to $6 / 24$. In contemporary times, patients who had occlusion therapy at advance ages have continued to show improved vision. ${ }^{11-13}$

Compliance issues, seen in our patient, are impediments to occlusion therapy in grown-ups. ${ }^{14}$ Our patient being a female might border about the cosmesis of tapping her eye or having to answer questions about the taped eye. It can be said that where a patient is well motivated occlusion therapy could still be tried even long after amblyogenic period especially if amblyopia results from myopic anisometropia. A multi-centre randomized clinical trial is advocated among grown-up anisomyopic amblyopic patients to establish the full range of benefits of occlusion therapy including appropriate occlusion dose in this age group.

\section{REFERENCES}

1. Paysse EA. Photorefractive keratectomy for anisometropic amblyopia in children. Trans Am Ophthalmol Soc. 2004; 102: 341-372.

2. Doshi N, Rodriguez MFL. Amblyopia. Am Fam Physician. 2007; 75(3): 361-367.

3. Megbelayin EO. Prevalence of Amblyopia among Secondary School Students in Calabar, SouthSouth Nigeria. Niger J Med 2012; 21(4): 407-411.

4. Enrique MC, Pedro GH, Jorge LA. Reversal of Myopic Anisometropic Amblyopia With Phakic Intraocular Lens Implantation. J Refract Surg 2001; 17: 460-462

5. Lithander J, Sjostrand J. Anisometropic and strabismic amblyopia in the age group 2 years and above: a prospective study of the results of treatment. Br J Ophthalmol. 1991; 75: 111-116.

6. Flynn JT, Schiffman J, Feuer W, et al. The therapy of amblyopia: an analysis of the results of amblyopia therapy utilizing the pooled data of published studies. Trans Am Ophthalmol Soc. 1998; 96: 431450.

7. Alemayehu W, Abonesh G. Profile of Amblyopia at the Pediatric Ophthalmology Clinic of Menilik II Hospital, Addis Ababa. Ethiop. J. Health Dev. 2008; 22(2): 201-205.

8. Weakley DR., Jr The association between anisometropia, amblyopia, and binocularity in the absence of strabismus. Trans Am Ophthalmol Soc. 1999; 97: 987-1021.

9. Weakley DR., Jr The association between nonstrabismic anisometropia, amblyopia, and subnormal binocularity. Ophthalmology 2001;108:163171.

10. Prakash P. Amblyopia in myopia. Indian J Ophthalmol 1983; 31: 807-812.

11. Attebo K, Mitchell P, Cumming R., Smith W, Jolly N, Sparkes R. Prevalence and causes of amblyopia in an adult population. Ophthalmology 1998; 105:154-159.

12. Wang JJ, Foran S, Mitchell P. Age specific prevalence and causes of bilateral and unilateral visual impairment in older Australians: The Blue Mountains Eye Study. Clin Exp Ophthal 2000; 28: 268273.

13. Quah BL, Tay MT, Chew ST, Lee LK. A study of amblyopia in 18-19 year old males. Singapore Med J. 1991; 32:126-129. 
14. Nucci P, Alfarano R, Piantanida A, Brancato R.

Compliance in antiamblyopia occlusion therapy. Acta Ophthalmol (Copenh) 1992; 70(1): 128-131

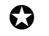

